\title{
Long-Term Response in a Patient with del(5q) Myelodysplastic Syndrome Who Discontinued Lenalidomide and Obtained a Good Response and Tolerance to Rechallenge
}

\author{
Francesco Pisani $^{a} \quad$ Giulia Orlandi $^{\mathrm{b}} \quad$ Roberta Merola $^{\mathrm{b}}$ \\ Departments of ${ }^{\mathrm{a}} \mathrm{Hematology}$ and ${ }^{\mathrm{b}} \mathrm{Clinical}$ Pathology, Regina Elena National Cancer \\ Institute, Rome, Italy
}

\section{Key Words}

Myelodysplastic syndromes · $5 q-$ myelodysplastic syndrome $\cdot$ Lenalidomide

\begin{abstract}
Background: The introduction of the immunomodulatory drug lenalidomide has revolutionized the treatment of patients with myelodysplastic syndromes (MDS) and deletion of the long arm of chromosome 5. Treatment with lenalidomide results in transfusion independence in the majority of patients, but some questions remain unresolved, among them the duration of treatment. Moreover, a number of unexpected long-term remissions in patients who stopped lenalidomide for various reasons have been observed. Case Report: We report the case of a 60-year-old Caucasian male with deletion of the long arm of chromosome 5 and International Prognostic Scoring System (IPSS)-defined low-risk MDS who was treated with lenalidomide, achieving complete cytogenetic remission and erythroid response. After tapering off and interrupting the treatment, the patient relapsed and showed a new response by lenalidomide retreatment. Six years after the initial treatment, we registered a durable erythroid long-term response and good tolerance, but there was no evidence of a very profound cytogenetic response compared to using lenalidomide as a first-line treatment. Cytogenetic and fluorescence in situ hybridization together with hemoglobin level, mean corpuscular volume (MCV) and vitamin $B_{12}$ level helped us to monitor the patient response; during the various phases of lenalidomide treatment, $\mathrm{MCV}$ and vitamin $\mathrm{B}_{12}$ normalization correlated with good response. Conclusion: Lenalidomide interruption and rechallenge in
\end{abstract}


some $5 q-$ MDS patients, with low risk according to the IPSS, is safe and feasible but does not result in a profound cytogenetic response.

(c) 2014 S. Karger AG, Basel

\section{Introduction}

Myelodysplastic syndromes (MDS) are clonal bone marrow disorders characterized by ineffective bone marrow hematopoiesis, peripheral blood cytopenias and risk of transformation to acute myeloid leukemia (AML). Patients are stratified according to the International Prognostic Scoring System (IPSS) into low-, intermediate-1-, intermediate-2- and highrisk categories [1]. Among cytogenetic abnormalities, partial or complete deletion of the long arm of chromosome 5 [del( $5 q)$ ] is the most common cytogenetic abnormality found in MDS patients, occurring in $10-15 \%$ of all de novo MDS patients $[2,3]$ and in up to $30 \%$ of cases with abnormal karyotype. The prognosis of MDS cases with del(5q) worsens with additional cytogenetic changes and increase in blast percentages [4]. Treatment with the immunomodulatory drug lenalidomide has set a new standard for the management of low/intermediate1-risk MDS with 5q- in transfusion-dependent patients [5]. Lenalidomide suppresses the growth of MDS progenitors harboring 5q-, giving rise to a high frequency of transfusion independence (TI) and cytogenetic response and promotes erythroid lineage competence and colony-forming capacity [6]. Lenalidomide may restore transcriptional response to endogenous erythropoietin in MDS progenitors, suggesting that lenalidomide enhances cellular responsiveness to erythropoietin stimulation; moreover, p53 expression in erythroid precursors decreased in lenalidomide responders but is upregulated upon the emergence of resistance to lenalidomide [7].

The current treatment recommendation is to treat $5 q$ - with lenalidomide until relapse or transfusion dependence or progressive disease [8]. Consequences of the long-term effects of continuous immunomodulation with lenalidomide are unknown, and the question whether interruption of lenalidomide treatment is beneficial for patients in remission has never been formally addressed [9].

We herein report a patient with MDS with isolated 5q deletion and IPSS-defined lowrisk MDS, who was treated with lenalidomide, achieving complete cytogenetic remission and erythroid response, and who after tapering off and interrupting the treatment relapsed. A new response was observed after re-exposure to lenalidomide, showing durable erythroid long-term response and good tolerance, but cytogenetic response was not very profound.

\section{Case Report}

A 60-year-old Caucasian male was first seen for the evaluation of macrocytic anemia, weakness and easy fatigue. Laboratory analyses confirmed the macrocytic anemia: hemoglobin (Hb) $10.6 \mathrm{~g} / \mathrm{dl}$; mean corpuscular volume (MCV) $109 \mathrm{fl}$ with a normal reticulocyte count; white blood cell count (WBC) was $3.34 \times 10^{9} / \mathrm{l}$; absolute neutrophil count (ANC) was $1.87 \times 10^{9} / \mathrm{l}$, and platelet count was $215 \times 10^{9} / \mathrm{l}$. Bone marrow aspirate and biopsy were performed revealing hypoplastic bone marrow with dyserythropoiesis, no ring sideroblasts were present, and micromegakaryocytes with single eccentric nuclei were also observed. Cytogenetic analysis showed 5q- with no other abnormalities; at least 10 metaphases and whenever possible 20-25 metaphases were analyzed by the classical cytogenetic method. The karyotype was written as 46,XY,del(5)(q31). A diagnosis of MDS with isolated 5q- was established, corresponding to the IPSS low-risk category. The serum erythropoietin level 
Pisani et al.: Long-Term Response in a Patient with del(5q) Myelodysplastic Syndrome Who Discontinued Lenalidomide and Obtained a Good Response and Tolerance to Rechallenge

was $\leq 200 \mathrm{IU} / \mathrm{l}$ and the patient was transfusion-independent; therefore, we observed him periodically.

After 11 months, he showed a decline in the Hb level: Hb was $9.8 \mathrm{~g} / \mathrm{dl}$, MCV $112 \mathrm{fl}$ and the serum erythropoietin level was less than $200 \mathrm{IU} / \mathrm{l}$. We then treated the patient with 40,000 IU of erythropoietin $\alpha$ biweekly for 6 months. Despite erythropoietin support the patient had a continuous decline in Hb levels. After 7 months of this treatment, $\mathrm{Hb}$ was 7.9 $\mathrm{g} / \mathrm{dl}$, MCV was $110 \mathrm{fl}$, vitamin $\mathrm{B}_{12}$ was $930 \mathrm{pg} / \mathrm{ml}$ (range 191-663), the bone marrow showed an increased dyserythropoiesis, and the fluorescence in situ hybridization (FISH) analysis, using LSI5q31 (EGR1)/D5S23, D5S721 probe (Abbott, Molecular Inc., Des Plaines, Ill., USA) on 200 interphase nuclei, permitted to detect a higher percentage of cells with 5qsince the diagnosis (65 vs. $45 \%$ ). The patient refused transfusion and lenalidomide was initiated at a dose of $10 \mathrm{mg} /$ day for 21 days every 4 weeks, together with aspirin as thromboprophylaxis (ANC was $1.6 \times 10^{9} / \mathrm{l}$ and platelet count $301 \times 10^{9} / \mathrm{l}$ ). Weekly blood controls showed grade 3 neutropenia and growth factor (G-CSF) support was initiated biweekly from the second cycle of treatment to the fifth.

After 5 cycles of standard treatment, the patient obtained complete hematological and cytogenetic remission: Hb was $12.6 \mathrm{~g} / \mathrm{dl}$, MCV $98 \mathrm{fl}$, vitamin $\mathrm{B}_{12} 600 \mathrm{pg} / \mathrm{ml}$, WBC $4.4 \times 10^{9} / \mathrm{l}$, ANC $3.3 \times 10^{9} / \mathrm{l}$, and platelet count was $135 \times 10^{9} / \mathrm{l}$. We suspended the growth factor support and tapered off the dose of lenalidomide (initially $5 \mathrm{mg}$ for 21 days every 4 weeks for 3 cycles and subsequently $5 \mathrm{mg}$ every other day for 21 days every 4 weeks for 6 cycles). Then we treated him with $5 \mathrm{mg}$ biweekly for 3 weeks of every 28-day cycle for 12 cycles, remaining transfusion independent and in complete hematological and cytogenetic remission (fig. 1; table 1), with a range of platelet count between 149 and $128 \times 10^{9} / \mathrm{l}$. After 1 year of this schedule, the patient had a cytogenetic relapse with $2 / 10$ metaphases and $18 \%$ interphase nuclei showing a 5q- (fig. 1), but he remained transfusion independent ( $\mathrm{Hb} 13.9$ $\mathrm{g} / \mathrm{dl}, \mathrm{MCV} 100 \mathrm{fl}$, platelet count $128 \times 10^{9} / \mathrm{l}$, WBC $3.5 \times 10^{9} / \mathrm{l}$, ANC $1.09 \times 10^{9} / \mathrm{l}$ and vitamin $\mathrm{B}_{12} 831 \mathrm{pg} / \mathrm{ml}$ ). However, we decided to stop lenalidomide treatment and observed him for 14 months; at this time, 5q- was detected in $8 / 10$ metaphases and in $60 \%$ of the interphase nuclei ( $\mathrm{Hb} 12.1 \mathrm{~g} / \mathrm{dl}$, MCV $108 \mathrm{fl}$, vitamin $\mathrm{B}_{12} 792 \mathrm{pg} / \mathrm{ml}$, platelet count $\left.182 \times 10^{9} / \mathrm{l}\right)$; the patient was rechallenged with lenalidomide $10 \mathrm{mg}$ for 21 days every 4 weeks (fig. 1). No GCSF was used but the patient restarted thromboprophylaxis with aspirin. He responded to the reintroduction of lenalidomide, achieving complete cytogenetic remission after 3 cycles and continuing lenalidomide at a standard dose of $10 \mathrm{mg}$ until the sixth course [Hb was 14 $\mathrm{g} / \mathrm{dl}$ (fig. 2), MCV decreased to $99 \mathrm{fl}$ and vitamin $\mathrm{B}_{12}$ decreased to $442 \mathrm{pg} / \mathrm{ml}$, platelet count $122 \times 10^{9} / \mathrm{l}$, WBC $3.03 \times 10^{9} / \mathrm{l}$, and ANC $\left.2.2 \times 10^{9} / \mathrm{l}\right]$. Cytogenetic and FISH analysis were negative and no blasts were detected in bone marrow aspirate. We reduced the dose at 10 mg biweekly for 3 weeks every 28 days for 4 months; then $5 q$ - was detected in $44 \%$ interphase nuclei (fig. 1), karyotype was not available, Hb was $13.5 \mathrm{~g} / \mathrm{dl}, \mathrm{MCV} 100 \mathrm{fl}$ and vitamin $B_{12} 280 \mathrm{pg} / \mathrm{ml}$. Then we changed the schedule with the dose of $5 \mathrm{mg}$ for 21 days every 4 weeks for 6 courses, when $4 / 10$ metaphases and 22\% of interphase nuclei showed 5q-; Hb was 13.9 g/dl, MCV 96 fl, vitamin $\mathrm{B}_{12}$ 1,344 pg/ml, bone marrow blasts 3\%, and a partial cytogenetic remission was obtained (fig. 1). Here we increased lenalidomide to $10 \mathrm{mg}$ for 21 days every 4 weeks ( 6 cycles). In this period, we observed grade 3 neutropenia, and we started G-CSF once a week for 5 months. After these 6 cycles, $1 / 10$ metaphases and $4 \%$ of interphase nuclei showed 5q-, no bone marrow blasts were observed, but the development of a new independent clone was detected by cytogenetic and FISH analyses, containing loss of the $\mathrm{Y}$ chromosome in $2 / 10$ metaphases and in $28 \%$ of interphase nuclei (fig. 1). Other parameters were: $\mathrm{Hb} 14 \mathrm{~g} / \mathrm{dl}$, MCV $97 \mathrm{fl}$, vitamin $\mathrm{B}_{12} 448 \mathrm{pg} / \mathrm{ml}$, platelet count $105 \times 10^{9} / \mathrm{l}$, WBC $3.3 \times 10^{9} / \mathrm{l}$, and ANC $1.2 \times 10^{9} / \mathrm{l}$. 
Pisani et al.: Long-Term Response in a Patient with del(5q) Myelodysplastic Syndrome Who Discontinued Lenalidomide and Obtained a Good Response and Tolerance to Rechallenge

We continued lenalidomide treatment for another 3 cycles at $10 \mathrm{mg}$ dose, when $1 / 10$ metaphases and 3\% of interphase nuclei showed 5q- and 3/10 metaphases and 31\% of interphase nuclei were positive for loss of the Y chromosome with $\mathrm{Hb} 14.3 \mathrm{~g} / \mathrm{dl}, \mathrm{MCV} 98 \mathrm{fl}$, vitamin $\mathrm{B}_{12} 411 \mathrm{pg} / \mathrm{ml}$, platelet count $117 \times 10^{9} / \mathrm{l}$, WBC $2.9 \times 10^{9} / \mathrm{l}$, and ANC $1.3 \times 10^{9} / \mathrm{l}$. At this point, we decided to reduce lenalidomide at $10 \mathrm{mg}$ every other day for 21 days of every 28-day cycle, and this schedule was administered for 6 cycles; after that, 8/12 metaphases and $24 \%$ of interphase nuclei showed $5 q-$ and 3/12 metaphases and $28 \%$ of interphase nuclei were positive for loss of the $\mathrm{Y}$ chromosome with bone marrow blasts 3\%, $\mathrm{Hb} 12.2$ $\mathrm{g} / \mathrm{dl}$, MCV $102 \mathrm{fl}$, vitamin $\mathrm{B}_{12} 744 \mathrm{pg} / \mathrm{ml}$, platelet count $132 \times 10^{9} / \mathrm{l}$, WBC $2.5 \times 10^{9} / \mathrm{l}$, and ANC $1.08 \times 10^{9} / \mathrm{l}$. Then we increased lenalidomide dosage at $10 \mathrm{mg}$ for 21 days of every 4week cycle; after 6 cycles, $7 \%$ of interphase nuclei showed $5 q-$ and $38 \%$ loss of Y chromosome, bone marrow blasts $2 \%$, Hb was $13.6 \mathrm{~g} / \mathrm{dl}, \mathrm{MCV} 97 \mathrm{fl}$, vitamin $\mathrm{B}_{12} 682 \mathrm{pg} / \mathrm{ml}$, platelet count $91 \times 10^{9} / \mathrm{l}$, WBC $2.42 \times 10^{9} / \mathrm{l}$, and ANC $1.17 \times 10^{9} / \mathrm{l}$; at present, this schedule is still administered. The patient has never taken a supplement of vitamin $B_{12}$, he continues thromboprophylaxis with aspirin $(100 \mathrm{mg} /$ day $)$, no thrombotic events have so far been observed, he has a good quality of life, assessed with the Functional Assessment of Cancer Therapy-Anemia (FACT-An) questionnaire [10], and he continues to perform daily sport activity by jogging for $2 \mathrm{~h}$ a day since the first achievement of complete hematological and cytogenetic remission.

\section{Discussion}

Consequences of the long-term effects of continuous immunomodulation with lenalidomide are unknown. Furthermore, there is limited evidence that discontinuation of lenalidomide may lead to long-term transfusion freedom.

Our patient with IPSS-defined low-risk MDS with isolated 5q- within 12 weeks of initiating lenalidomide $10 \mathrm{mg}$ achieved TI and complete hematological and cytogenetic remission. He maintained TI from February 2008 until March 2014 (6 years) also stopping lenalidomide for 13 months (December 2010 to December 2011); in many cases reported in the literature, the median duration of TI is 2 years. We observed a correlation between cytogenetic response and normalization of MCV and vitamin $B_{12}$ levels, with a decrease of the amount of abnormal interphase nuclei, showing 5q-, detected by FISH.

Long-term outcome data indicate that a cytogenetic response to lenalidomide therapy might offer a survival advantage, compared with cytogenetic nonresponders, and lenalidomide treatment does not increase AML progression risk, among lower-risk, transfusiondependent MDS patients, but instead confers a possible benefit in red blood cell transfusiondependent patients with del(5q) low- or intermediate-1-risk MDS $[9,11]$. In our patient, after 5 cycles of standard treatment, we obtained complete hematological and cytogenetic remission; we then tapered off the dose of lenalidomide, and the patient remained transfusion independent and in complete hematological and cytogenetic remission for further 9 months (fig. 1, fig. 2). In November 2009, the patient had a cytogenetic relapse remaining transfusion independent; we, however, stopped lenalidomide and observed him. Subsequently the patient was rechallenged with lenalidomide and he responded to the reintroduction of lenalidomide intervention as other cases described by Giagounidis et al. [9], achieving complete cytogenetic remission after 3 cycles and continuing this dosage until the sixth course (July 2011). We continued to modulate the dose of lenalidomide on the basis of FISH analysis (table 1); in our patient, the reappearance of $5 q$ - was not equivalent to transfusion dependence and as in other patient series he remained transfusion-free, without being 
exposed for many months to any medication [9]. MCV and vitamin $B_{12}$ levels, in our case, have always correlated with the hematologic and cytogenetic response, normalizing when the patient achieved complete remission and rising again to more than the normal reference value when the patient relapsed, indicating in our patient a variation in the promotion of effective erythropoiesis. Therefore, MCV and vitamin $B_{12}$ values may be very simple parameters to monitor regularly. To our knowledge, this observation has never been stressed in previous publications and monitoring those easily available parameters could help, together with cytogenetic and hematological analyses, to follow the response and eventually to modulate the lenalidomide schedule, in a manner as to reduce drug toxicity; specially if the patients maintain a good hematological response with TI, at least in low-risk MDS patients. Previously Sekeres et al. [12] analyzed the relationship between the development of treatment-induced cytopenias and the response to therapy in MDS. They specifically found that among lower-risk MDS patients with del(5q) whose platelet count decreased by $\geq 50 \%$, packed red blood cell $\mathrm{TI}$ was likely to be achieved, as compared with patients not experiencing the same magnitude of thrombocytopenia; however, they did not analyze MCV and vitamin $\mathrm{B}_{12}$ as parameters that predict the response. Also in our case we registered a platelet count of less than $150 \times 10^{9} / \mathrm{l}$ (range 91-149 $\times 10^{9} / \mathrm{l}$ ), except after 14 months of stopping treatment, when the platelet count was $182 \times 10^{9} / \mathrm{l}$ and $5 \mathrm{q}-$ was detected in $60 \%$ of interphase nuclei; however, we still observed TI but $\mathrm{Hb}$ decreased to $12.1 \mathrm{~g} / \mathrm{dl}$. A platelet count decline was again evident after the restart of lenalidomide treatment; a platelet drop was also present when we used the schedule $5 \mathrm{mg}$ for 21 days or every other day or biweekly. With the dose of $5 \mathrm{mg}$ biweekly that, compared to the schedule of $5 \mathrm{mg}$ every other day [13], was never published, we still had TI and a progressive normalization of the platelet count but eventually an increase in 5q- and interphase nuclei.

Six and a half years after the diagnosis and 5 years after the onset of lenalidomide treatment, we registered in our patient the development of a new independent clone with the loss of the Y chromosome, detected in both conventional cytogenetics and FISH. The deletion of the $\mathrm{Y}$ chromosome in men was not considered abnormal in a previous study [5]; the clinical association between the loss of the Y chromosome and AML/MDS is still debated because both phenomena are related to aging. It has been demonstrated that normal males start to lose the $Y$ chromosome in bone marrow cells at the age of 60 years, and in a series of 142 patients with loss of $Y$ chromosome the cases with karyotype, demonstrating less than $100 \%$ loss of the Y chromosome, were not statistically associated with AML/MDS [14].

Our patient was 60 years old at diagnosis and developed loss of $Y$ chromosome in about $30 \%$ of cells at the age of 65,5 years after the start of lenalidomide treatment, with periods of discontinuation of treatment and dose tapering. Clearly, the loss of Y chromosome is still a gray zone and we will thus continue to monitor our patient.

Treatment with lenalidomide improved health-related quality of life (FACT-An); improvements were apparent at week 12 and were significantly demonstrated through 6 years, with absolute change from baseline FACT-An scores exceeding 7 points.

Neutropenia grade 3 was the most common treatment-associated adverse event, no venous thromboembolism was registered, but aspirin as thromboprophylaxis was administered. Current recommendations state that treatment with lenalidomide in del(5q) MDS should be continued until disease progression [8]. The question whether interruption of lenalidomide treatment is beneficial in patients in remission has never been formally addressed. This concept is appealing for several reasons: first, it would reduce costs and side effects; second, the progression to AML in 5q- disease is not entirely understood. Reducing lenalidomide exposure would prevent a notional selective pressure of the compound on 5qstem cells, facilitating disease progression. It has been speculated that continuous admin- 
Pisani et al.: Long-Term Response in a Patient with del(5q) Myelodysplastic Syndrome Who Discontinued Lenalidomide and Obtained a Good Response and Tolerance to Rechallenge

istration of lenalidomide may lead to selective pressure on stem cells that induces genomic instability, resulting in acute leukemia transformation. Our patient, as other cases in the literature, remained in long-term complete cytogenetic remission without lenalidomide treatment, before showing reappearance of 5q- [15]. The reappearance of 5q- is not equivalent to transfusion dependence and many patients remain transfusion free for years without being exposed to lenalidomide; in our case, the restart of lenalidomide treatment did not result in a very profound cytogenetic response compared to using lenalidomide as a first-line treatment.

\section{Conclusion}

In our case, lenalidomide interruption was safe and feasible as also reported in other MDS patients with 5q- of low and intermediate-1 risk according to the IPSS. MCV and vitamin $B_{12}$ levels could help together with platelet count decline to predict the response.

\section{References}

1 Greenberg P, Cox C, LeBeau MM, Fenaux P, Morel P, Sanz G, et al: International scoring system for evaluating prognosis in myelodysplastic syndromes. Blood 1997;89:2079-2088.

-2 Haase D, Germing U, Schanz J, Pfeilstocker M, Nosslinger T, Hildebrandt B, et al: New insights into the prognostic impact of the karyotype in MDS and correlation with subtypes: evidence from a core dataset of 2,124 patients. Blood 2007;110:4385-4395.

-3 Solè F, Luño E, Sanzo C, et al: Identification of novel cytogenetic markers with prognostic significance in a series of 968 patients with primary myelodysplastic syndromes. Haematologica 2005;90:1168-1178.

-4 Giagounidis A, Germing U, Strupp C, Hildebrandt B, Heinsch M, Aul C: Prognosis of patients with del(5q) MDS and complex karyotype and the possible role of lenalidomide in this patients subgroup. Ann Hematol 2005;84:569-571.

-5 List A, Dewald G, Bennet J, Giagounidis A, Raza A, Feldman D, Powell B, Greenberg P, Thomas D, Stone R, Reeder C, Wride K, Patin J, Schmidt M, Zeldis J, Knight R: Lenalidomide in the myelodysplastic syndrome with chromosome 5q deletion. N Engl J Med 2006;355:1456-1465.

-6 Komrokji RS, Lancet J, Swern A, Chen N, Paleveda J, Lush R, Saba H, List A: Combined treatment with lenalidomide and epoetin alfa in lower-risk patients with myelodysplastic syndrome. Blood 2012;120:3419-3424.

7 Wei S, Chen X, McGraw K, Zhang L, Komrokji R, Clark J, Caceres G, Billingsley D, Sokol L, Lancet J, Fortenbery N, Zhou J, Eksioglu EA, Sallman D, Wang H, Epling-Burnette PK, Djeu J, Sekeres M, Maciejewski JP, List A: Lenalidomide promotes $\mathrm{p} 53$ degradation by inhibiting MDM2 auto-ubiquitination in myelodysplastic syndrome with chromosome $5 q$ deletion. Oncogene 2013;32:1110-1120.

8 Giagounidis A, Fenaux P, Mufti GJ, Muus P, Platzbecker U, Sanz G, et al: Practical recommendations on the use of lenalidomide in the management of myelodysplastic syndromes. Ann Hematol 2008;87:345-352.

-9 Giagounidis A, Kulasekararaj A, Germing U, Radkowski R, Haase S, Petersen P, Göhring G, Busche G, Aul C, Mufti GJ, Platzbecker U: Long-term transfusion independence in del(5q) MDS patients who discontinue lenalidomide. Leukemia 2012;26:855-858.

$>10$ Cella D: The functional assessment of cancer therapy-anemia (FACT-An) scale: a new tool for the assessment of outcomes in cancer anemia and fatigue. Semin Hematol 1997;34(suppl 2):13-19.

-11 Kuendgen A, Lauseker M, List AF, Fenaux P, Giagounidis A, Brandeburg NA, Backstrom J, Glasmacker A, Hasford J, Germing U: Lenalidomide does not increase AML progression risk in RBC transformationdependent patients with low- or intermediate-1-risk MDS with del(5q): a comparative analysis. Leukemia 2013;27:1072-1079.

-12 Sekeres M, Maciejewski JP, Giagounidis A, Wride K, Knight R, Raza A, List A: Relationship of treatmentrelated cytopenias and response to lenalidomide in patients with lower-risk myelodysplastic syndromes. J Clin Oncol 2008;26:5943-5949.

13 Defina M, Rondoni M, Gozzetti A, Aprile L, Chitarrelli I, Fabbri A, Lauria F, Bocchia M: Lenalidomide on alternative days is effective in myelodysplastic syndrome with 5q-deletion. Br J Haematol 2009;148:483484.

14 Zhang LJ, Shin ES, Yu X, Li B: Molecular genetic of Y chromosome loss in male patients with hematological disorder. Chin Med J 2007;120:2002-2005. 


\section{Case Reports in Oncology}

\begin{tabular}{l|l}
\hline Case Rep Oncol 2014;7:277-284 \\
\hline DOI: $10.1159 / 000362643$ & $\begin{array}{l}\text { C 2014 S. Karger AG, Basel } \\
\text { www.karger.com/cro }\end{array}$ \\
\hline
\end{tabular}

Pisani et al.: Long-Term Response in a Patient with del(5q) Myelodysplastic Syndrome Who Discontinued Lenalidomide and Obtained a Good Response and Tolerance to Rechallenge

15 Tehranchi R, Woll PS, Anderson K, Buza-Vidas N, Mizukami T, Mead AJ, et al: Persistent malignant stem-cells in del(5q) myelodysplasia in remission. N Engl J Med 2010;363:1025-1037.

Table 1. Time and lenalidomide treatment schedules

\begin{tabular}{|c|c|}
\hline October 2007 & Lenalidomide $10 \mathrm{mg}, 1-21$ days \\
\hline January 2008 & After 5 cycles, lenalidomide $10 \mathrm{mg}, 1-21$ days \\
\hline February 2008 & Lenalidomide $5 \mathrm{mg}, 1-21$ days \\
\hline April 2008 & After 3 cycles, lenalidomide $5 \mathrm{mg}, 1-21$ days \\
\hline October 2008 & $\begin{array}{l}\text { After } 6 \text { cycles, lenalidomide } 5 \mathrm{mg} \text { every other day, } \\
1-21 \text { days }\end{array}$ \\
\hline November 2009 & $\begin{array}{l}\text { After } 12 \text { cycles, lenalidomide } 5 \text { mg biweekly, } \\
\text { 1-21 days }\end{array}$ \\
\hline February 2011 & After 14 months, without lenalidomide \\
\hline May 2011 & After 3 cycles, lenalidomide $10 \mathrm{mg}, 1-21$ days \\
\hline August 2011 & After 6 cycles, lenalidomide $10 \mathrm{mg}, 1-21$ days \\
\hline November 2011 & $\begin{array}{l}\text { After } 3 \text { cycles, lenalidomide } 10 \text { mg biweekly, 1-21 } \\
\text { days }\end{array}$ \\
\hline April 2012 & After 6 cycles, lenalidomide $5 \mathrm{mg}, 1-21$ days \\
\hline November 2012 & After 6 cycles, lenalidomide $10 \mathrm{mg}, 1-21$ days \\
\hline March 2013 & After 9 cycles, lenalidomide $10 \mathrm{mg}, 1-21$ days \\
\hline September 2013 & $\begin{array}{l}\text { After } 6 \text { cycles, lenalidomide } 10 \mathrm{mg} \text { every other } \\
\text { day, 1-21 days }\end{array}$ \\
\hline March 2014 & After 6 cycles, lenalidomide $10 \mathrm{mg}, 1-21$ days \\
\hline
\end{tabular}

FISH\% - Y 8 Karyotype\% - Y $\square$ FISH $\%$ del(5q) $\square$ karyotype\% del(5q)

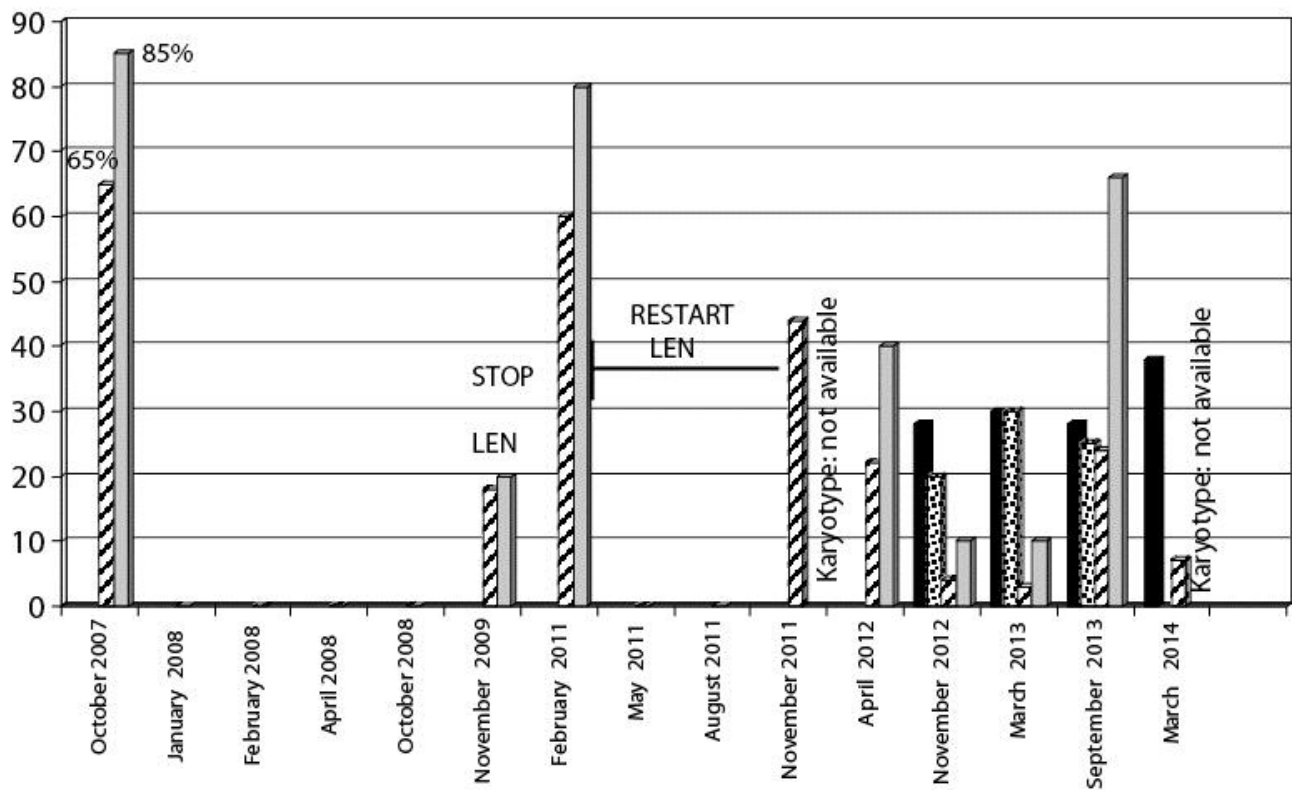

Fig. 1. Sequential bone marrow karyotype and FISH studies: percentage of del(5q) and Y chromosome loss from October 2007 to March 2014 during the various phases of lenalidomide treatment. 
Pisani et al.: Long-Term Response in a Patient with del(5q) Myelodysplastic Syndrome Who Discontinued Lenalidomide and Obtained a Good Response and Tolerance to Rechallenge

$\mathrm{g} / \mathrm{dL}$

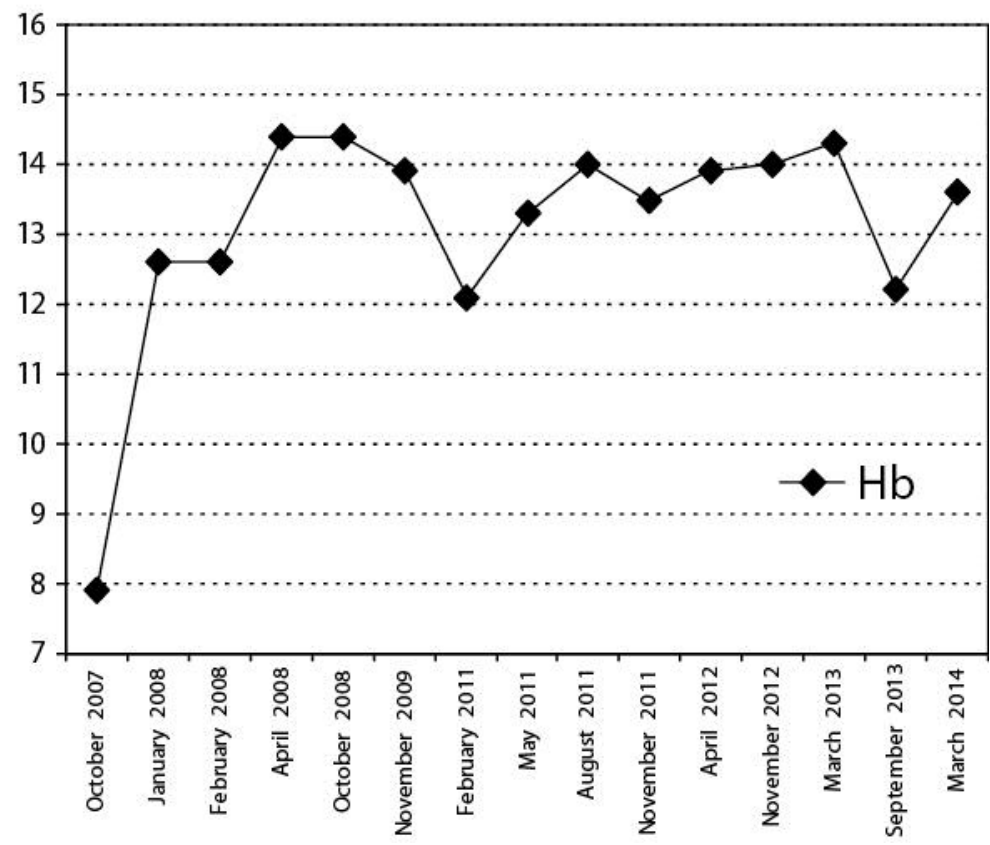

Fig. 2. Changes in Hb levels from October 2007 to March 2014 under various phases of lenalidomide treatment. 